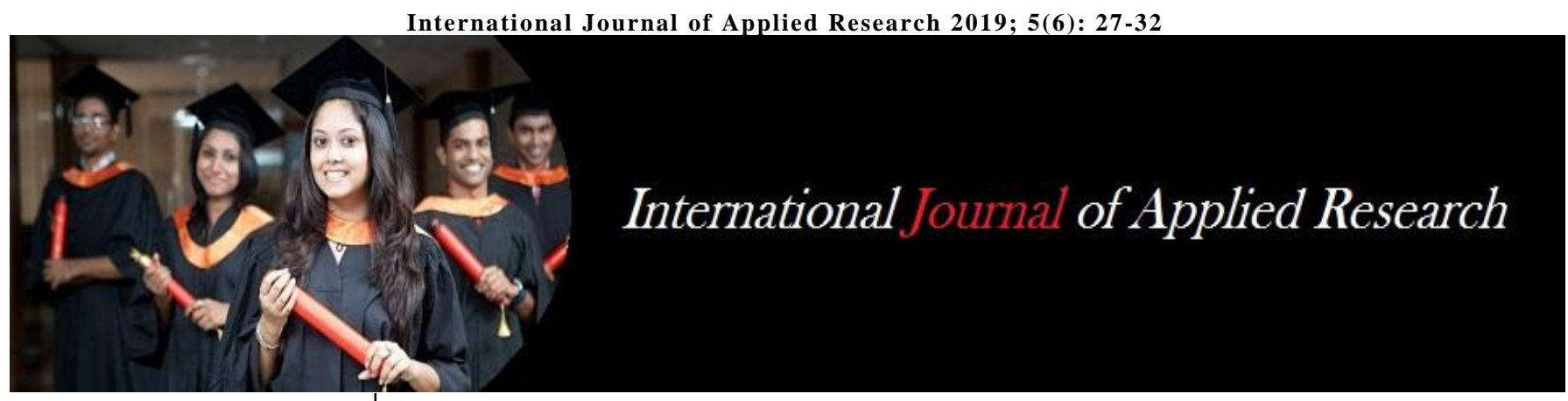

ISSN Print: $2394-7500$ ISSN Online: 2394-5869 Impact Factor: 5.2

IJAR 2019; 5(6): 27-32 www.allresearchjournal.com

Received: 16-04-2019 Accepted: 20-05-2019

Moses Jeremiah Barasa Kabeyi Lecturer, Department of Mechanical and Manufacturing Engineering, University of Nairobi, Kenya
Correspondence

Moses Jeremiah Barasa Kabeyi Lecturer, Department of mechanical and Manufacturing Engineering, University of Nairobi, Kenya

\section{Organizational strategic planning, implementation and evaluation with analysis of challenges and benefits for profit and nonprofit organizations}

\author{
Moses Jeremiah Barasa Kabeyi
}

\begin{abstract}
Strategic planning and management is the way to go for organizations to prepare themselves to sustain and overcome competion in market places. It is important for all organizations in private sector, public sector and nonprofit organizations. It is a process that begins with self-assessment and realization and then reorganization to compete in a business environment. Business strategies form the basis of survival in a competitive environment and should therefore be well developed by the right people and the right organizational levels. Strategy formulation and implementation should be linked by an evaluation strategy to realize strategy success otherwise the strategies remain useless paperwork. Strategy implementation challenges include political interference, limited resources and global economic situations that may be beyond the organizations' control and so organizations should monitor the internal and external environment and make changes or adjustments to prevent strategy failure. This can be realized by effectively evaluating strategy implementation process. A good strategic plan will give significant benefits to organizations like increased profitability and better corporate governance. Strategic management however is expensive, requires significant resources and investment in market research and other resources yet does not always guarantee success. To be successful in strategic planning and implementation organizations, should invest in market research and forecasting, adequate budgeting, as well as recruitment, training and motivation of qualified personnel and having a holistic approach in strategy formulation and implementation by bringing everybody in the organization to contribute and participate. Strategies should be creative and innovative while the execution should be both effective and efficient. Quick and effective feedback will enhance monitoring and evaluation and facilitate successful strategy implementation. Organizations should be customer oriented to deal with competition and hence proper strategy formulation and implementation. It should however be noted that having a strategic plan does not always guarantee success. However, a well-crafted, innovative and creative plan that is well executed will guarantee success. An effective strategy should start with a SWOT analysis which will enable the organization to build on its strengths and utilize opportunities while controlling or managing threats and weaknesses.
\end{abstract}

Keywords: Strategic management, strategic plan, strategy monitoring, benefits of strategic management, strategic planning for nonprofits, strategy evaluation, limitations of strategic planning and management.

\section{Introduction to strategic management}

Strategic management is defined as the art and science of formulating, implementing, and evaluating cross-functional decisions that enable an organization to achieve its objectives, while strategic planning is the process of defining an organizations direction, and making decisions on allocating its resources to pursue this strategy. Strategic planning is also defined as organizational management activity that is used to set priorities, consolidate energy and resources, strengthen operations capability, ensure stakeholders and workers are working toward common goals, and assess and align organization's direction in with changing environment (David, 2011; Dyer, Godfrey, Jensen, \& Bryce, 2016) ${ }^{[5,6]}$. Business strategy is a company's plan to get, competitive advantage in its markets. It is based on the theory that the company's leaders know how to succeed in a market and involves predictions about which markets are more attractive and how an organization can offer distinctive value to customers in those markets in a way that is difficult to copy by competitors (Godfrey, Jensen, \& Bryce, 2016) ${ }^{[6]}$. Therefore, strategic management is a process that begins with self-realization followed by positioning an organization to realize success in a competitive business environment. 


\subsection{Organizational strategy and levels}

According to Porter (1966) ${ }^{[16]}$ strategy is defined as the creation of a unique position involving a different set of activities. On his part Mintzberg (1994) ${ }^{[13]}$ views planning strategy, as intentions that are formulated and articulated by organizational leadership, to ensure surprise free implementation, in a controllable and practicable environment. Stewart (2004) as cited in Leskaj (2017) ${ }^{[12]}$ noted that strategy reinforces organizational survival in a competitive market by fore-seeing and dealing with challenges from competitors. It can therefore be noted that strategy is mainly about competing and surviving in the market through offering products, services and programs that are competitive against rival offerings.

\subsubsection{Levels of strategy}

There are different levels of organizational strategies. Tapera (2016) ${ }^{[19]}$ identified four levels namely corporate strategy, business strategy, functional strategy and operating strategies.

a. Corporate level strategy: This strategy is mainly concerned with selection of business, product and markets.

b. Business unit strategy: A strategic business unit may vary from organization to organization or industry to industry but may be a division, product line, profit center, geographical area etc. Strategic issues at business unit level include positioning a business against rivals, accommodating new technologies, influencing the nature of competition through vertical and horizontal integration, political lobbying and networking, etc.

c. Functional level strategies: Strategic issues at functional level are related to business processes and value chain. These strategies include marketing, manufacturing, research and development and finance.

d. Operational strategies: These are concerned with how each part of the business is organized to deliver the corporate and business-unit level strategic direction and functional strategies. Therefore, operational strategy focuses on issues of processes, human \& financial resources etc. These strategies include decisions at shop floor under supervisors and workers and include paying invoices, supply chain management, use of assets and other resources including employees in the best interest of the organization to realize competitive advantage.

\subsection{Long range planning and short-range planning}

This is a process by an organization which determines what it desires to look like or achieve at the end of a specified time period. Based on this intention, a vision is established for multi-year goals and objectives which states what the organization desires to realize and develop relevant plans of action. Long range planning covers multi-year projections of the organization, and thus it is usually not as specific as short term or operational level plans whose output is a work plan with detailed annual objectives, related activities, supporting tasks, specific procedures or methods, timelines, and responsibilities. Long range planning is focused on specific objectives and timelines than strategic planning (World Bank, 2011) ${ }^{[20]}$. Therefore long range planning is concerned with setting goals and objectives covering many years.

\subsubsection{Long range planning versus strategic planning}

Whereas strategic planning and long-range planning are somehow related, strategic planning generally places a greater emphasis on strategies for the organization to achieve its vision - while long-range planning defines the vision of the organization (World bank, 2011) ${ }^{[20]}$.

\subsubsection{Strategic planning}

The term strategic planning originated in the 1950s and became very popular between the mid-1960s and the mid1970s. During this period strategic planning was widely believed to be the answer for all problems facing organizations (David, 2011) ${ }^{[5]}$. On his part Hughes (2003) ${ }^{[9]}$ states strategic planning is a process that focuses on strategic and operational goals, objectives and strategies based on organizational policies, programs and activities that are designed to achieve the institution's aims and desirable results. According to Poister and Streib (2005) ${ }^{[17]}$, strategic planning needs to be action-oriented type of planning that is useful only if it is coupled to implementation and this is often the point where the process fails. According to the World Bank (2011) ${ }^{[20]}$, strategic planning is the process by which leaders of an organization determine what it intends to be in future and how it will reach this targeted level or position. Ong (2015) ${ }^{[15]}$ observed that strategic planning is a deliberate and formal process which analyzes current situation and set targets with commitment of resources aimed at realizing organizational competitive advantage. According to Bryson (1988), strategic planning It is "a disciplined effort to produce fundamental decisions and actions shaping the nature and direction of an organization's (or other entity's) activities within legal bounds."

Therefore, strategic planning is concerned with development of the organizational vision and determines the necessary priorities, procedures, and activities necessary to realize this stated vision. The organizational declared vision includes measurable goals which are realistic and attainable, but also challenging enough. Strategic planning involves setting targets and committing resources and discipline or order is a requirement for successful strategic planning

\subsubsection{Strategic plan}

The result of strategic planning process is a strategic plan which is a blue print for the organization as it moves into the future. According to Tapera (2016) ${ }^{[19]}$, a strategic plan is a tool for defining the organizational direction and therefore determines the objectives and goals of the organization that are as realistic as possible. Tapera further noted that strategic planning is a process whose result should be innovative and creative ideas which lay the foundation for an organizations future. Therefore, a good strategic plan should be founded on innovative and creative ideas.

\subsubsection{Strategic planning stages}

The strategic-management process consists of three stages, namely;
a. Strategy formulation,
b. Strategy Implementation, and
c. Strategy evaluation.

\section{Strategy formulation}

Strategy formulation includes developing a vision and mission, identifying an organization's external opportunities and threats, determining internal strengths and weaknesses, as well as establishing long-term objectives of the firm, generating alternative or competing strategies, and choosing strategies to be pursued by the organization. Strategy- 
formulation scope includes deciding about what and where to invest to, businesses to abandon altogether, resource allocation in terms of type and amount, decision on whether to expand operations or diversify, whether to enter international markets or withdraw, whether to merge or form joint ventures, and how to avoid a hostile takeover by other organizations in an aggressive business environment (David, 2011) ${ }^{[5]}$.

Members of several functions should be involved in the formulation stage and those to be involved should have credibility since other members follow their lead and see the importance of change. Therefore, strategy planners must have proper knowledge and understanding to educate others on what needs to be done and how to do it. Managers should organize the formulation effort successfully by allocating resources, responsibilities and authorities needed for successful planning (Brinkschröder, 2004) ${ }^{[3]}$.

The strategy formulation can identify wrong internal and external factors and so any strategy is not considered effective until it is implemented and ultimately creates value for the organization (Baroto, Arvand \& Ahmad, 2014) ${ }^{[1]}$. Therefore, strategy formulation should be closely linked to strategy implementation to avoid having a useless strategic plan. In other words, a strategy is only useful and effective if and only, it is implemented and gives positive results for the organization.

\section{Strategy implementation, success and failure}

According to Mohammed (2015) and Baroto, Arvand and Ahmad (2014) ${ }^{[1]}$ on why strategy implementation fails, $60 \%$ of organizations don't link strategy to budgeting process, $75 \%$ do not link employee incentives to strategy, $86 \%$ of business owners and managers spend less than one hour per month discussing strategy while $95 \%$ of typical workforce in organizations does not understand their organizational strategy. They noted that challenges of strategy implementation include political interference, limited resources and global economic situations that may be beyond the organizations control. Baroto, Arvand and Ahmad (2014) [1] further noted that $66 \%$ of corporate strategies are never implemented, $70 \%$ to $90 \%$ percent of organizations fail to realize the success of implementing their strategies, and only $63 \%$ of financial objectives envisioned by companies' strategies are achieved and that strategies most often fail due to ineffective execution.

According to Heracleous (2000) ${ }^{[8]}$, organizations can only realize sustained strategic success from continuous innovation and continuous adaptability and that companies that are out of touch with the environment to pursue a particular strategy effectively may initially realize success only to be blinded and fail in the long term due to failure to respond to environmental changes.The cost of failed implementations is significant and includes reduced employee morale, diminished trust in top management, and a more rigid organization due to increased employee cynicism which is often worse than skepticism (Heracleous 2000) ${ }^{[8]}$.

Therefore, strategy implementation may or may not succeed because of various factors both external and internal to the organization. The organization should study the business environment and react accordingly to ensure that strategies laid are not derailed. There are serious consequences for failed strategic implementation to individuals and the organization and should therefore be avoided.

\section{Strategy evaluation}

According to David (2011) ${ }^{[5]}$ Strategy evaluation includes three basic activities:

a. Examining the underlying bases of a firm's strategy

b. Comparing expected results with actual results

c. Taking corrective actions to ensure that performance conforms to plans

It is not possible to formulate and adjust strategy to changing circumstances without a good or effective strategy evaluation. Strategy evaluation forms an essential step in the process of guiding an enterprise I its strategy implementation process. Therefore, strategy evaluation should be an attempt to look beyond the obvious facts regarding the status of a business and instead appraise more fundamental factors and trends that influence business success (Glueck, 1980) ${ }^{[7]}$.

The following criterion can be used to test a business strategy

1) Consistency: The strategy must present mutually consistent goals and policies of the organization.

2) Consonance: The strategy must represent an adaptive response to the dynamic external environment and to the critical changes occurring during strategy implementation process.

3) Competitive advantage: The strategy must provide for the creation and maintenance of a competitive advantage in the selected area of activity of the organization

4) Feasibility: The strategy must be affordable and should not create unsolvable sub problems during its execution of strategy.

\section{Strategic planning and management process 2.1 Strategic management phases in business}

Strategic management process consists of five phases. According to Tapera (2016) ${ }^{[19]}$ the phases in strategic management are as follows;

1) Develop a strategic vision of where an organization desires to go and what products, markets and customers to focus.

2) Set objectives to be used in measuring progress and performance

3) Develop strategies to achieve

4) Implement and execute the accepted strategies both effectively and effectively.

5) Evaluate the performance and put in place corrective measures.

\subsection{Strategic management process for Non -Profit organizations}

Strategic planning for nonprofit organizations involves choosing the highest priority achievements that an organization is prepared to commit to over a period of three to five years. Strategic planning and management is as important to non-profits just like for private sector organizations. Bryson (1988) [4] remarked that strategic planning is likely to become part of the "repertoire of public and non-profit planners". Therefore strategic planning is important or useful to all types of organization whether for profit or nonprofit.

According to the World Bank (2011) ${ }^{[20]}$, there are many models and steps for strategic planning in nonprofit organizations. One approach which assumes cooperation between Board and staff involves the following steps;

a) Agree on a strategic planning process: Set up a strategic planning committee or task force for and have 
coordinating group consisting of a mix Board members, senior and middle level managers and representatives of technical and/or support staff, funders, sister organizations, and other stakeholders. Allocate enough staff time to the strategic planning process. It may be necessary to reduce the regular workloads or responsibilities of staff and Board members who are expected to play a key role in developing the strategic plan.

b) Carry out an environmental scan: This includes an external component of identifying and assessing opportunities and threats in the external environment and an internal component assessing organizational strengths and weaknesses, also called SWOT analysis.

c) Identify strategic planning issues: This includes identification or setting of priorities in terms of time or importance. This is followed by development organizational vision and then goals.

d) Develop the values, vision, and mission for the organization: At this stage consensus is developed on why the organization exists, what goals or outcomes it seeks to achieve what it stands for, and whom it serves in its day to day existence.

e) Develop Organizational Vision: It should be made clear and stated about where the organization is heading to in the long term say five years.

f) Develop a goals or organizational status statements: It is desirable to convert or transform the vision into a series of key goals for the organization, preferably in the form of status statements describing the organization.

g) Development strategies to reach the goals: Broad strategies, including current and new products and services. These strategies should be related to specific goals or address several goals.

h) Develop annual plans to address goals, objectives and work plans: Strategies need to reflect current conditions within the organization and its environment while the development of Objectives and annual work plans require both management and staff input.

i) Summarize the developed Strategic plan: This is in any acceptable format, but should include the outputs of each major step. The box at the end of this document provides one possibility.

j) Develop a monitoring and evaluation plan. This is to ensure that goals and objectives and strategies are monitored regularly, with strategies being revised and annual objectives developed yearly. Leadership should be involved in reviewing progress and assuring that strategies are changed as appropriate.

\section{Hurdles of implementing strategic planning}

According to Leskaj (2017) [12] organizations need to undertake strategies to meet their missions and objectives, but in the process, they face a myriad of challenges that threaten the successful implementation of this mission or implementing successful strategies in accordance with these plans. Leaders my fail to link their strategic planning efforts to other critical decision-making processes. The author observes that, having a strategic planning system in place is not a guarantee that an organization will achieve its strategic goals and objectives as planned.

Hughes (2003) ${ }^{[9]}$ acknowledges that there are more problems and constraints especially in public sector organizations as compared to the private sector organizations, yet he is of the view that public organizations could conceivably benefit from a strategic approach in their operations.

In his study on why organizations fail to implement strategies, Leskaj (2017) ${ }^{[12]}$ identified several reasons which include;

a) Poor or lack of strategy monitoring and evaluation: Some problems in measuring the performance. These problems in measuring the performance will be carried forward in the evaluation of performance and the management of change.

b) Organizational structure: Implementation of strategy often requires an organizational structure corresponding to identified needs and challenges. Where such is not put in place, strategy failure often occurs.

c) Human resources: Organizations, may fail to recruit, develop and motivate the right manpower for strategy formulation and implementation.

d) Motivation: Organizations may fail to adequately motivate members of staff using monetary and nonmoney means.

e) Lack of Financial resources: An organization may lack finance to implement strategies either by poor budgeting or financial constraints.

f) Generation and choice of strategy: failure to identify and develop the most appropriate strategies for the organization's strategic success. Low involvement in these strategic planning stages by the organization's members will reduce their motivation during the implementation of the strategy leading to failure or poor implementation.

\section{Benefits of utilizing strategic planning}

Organizations get significant benefits from strategic planning and management. According to the Braduţan and Sârbu (2012) ${ }^{[2]}$, Ong (2015) ${ }^{[15]}$, Heracleous (2000) ${ }^{[8]}$ and World Bank (2011) ${ }^{[20]}$, planning helps assure that an organization remains relevant and responsive in the business environment. The benefits include;

a) Strategic planning and management enables a firm to predict the future and prepare itself for it in a proactive manner as opposed to being reactive hence making them more adaptive and successful.

b) A strategic plan as a tool for defining organizational direction enables determination of objectives and goals that are as realistic as possible, and this facilitates consistency and stability in operations.

c) A successful strategic planning and management leads to increased market share and profitability as organizations get valuable insights of market trends, consumer segments and available product/service or program offering.

d) Strategic planning and management increase operational efficiency by providing a clear roadmap that facilitates alignment of activities and resources to realize well set and realistic goals leading to high efficiency in business operations.

e) It facilitates new program, product and service development by organizations in line with changing 
consumer needs and competition.

f) It enables an organization to investigate the future in an orderly and systematic way.

g) From a governance perspective, it enables the Board of Directors to set policies and goals to guide the organization, and provides a clear focus to the management

h) Often creditors or donors require strategic plans, and they provide a basis for setting Priorities, organizing work, and assessing progress for non-profits or nongovernmental organizations as well as for profit organizations.

Strategic planning promotes motivation and innovation since it involves managers at top levels who are committed to objectives and strategies and think of new ideas for implementation of strategies. It also provides motivation to people at lower levels when they know their efforts are contributing towards organizational goals. Through strategic management, risks are minimized since the process provides information needed to assess risk and frame strategies to minimize them and invest in safe business opportunities. Chances of making mistakes and choosing wrong objectives and strategies, thus, get reduced significantly. Risk is inherent in every business and failure to anticipate risk through strategic planning is almost sure to lead the business to failure Firms get significant financial benefits if they make strategic plans because firms that make strategic plans have good sales, low costs, and high profits (Tanuja, nd).

Hill and Jones (1998) ${ }^{[10]}$ and Tanaju (nd.) remarked that strategic planning produces real changes in the organizational climate, with benefits on their performance thus providing an enabling environment for the exercise of strategic management. Therefore, planning should be the starting point of strategic management while observing that, strategic planning unifies organizational activities and efforts towards the long-term goals of an organization. By focusing on specific goals, it makes it clear for staff members to know the direction towards which they are expected to move. Through strategic planning allocation of resources and attempts to meet the goals is facilitated through clear specifications laid out during strategy formulation and actual planning.

\section{Limitations of strategic planning and management}

In some cases, the environment is so dynamic that strategic or long-range planning becomes almost impossible. The same also may apply in cases where the economy deteriorates, or a hostile or unresponsive government takes charge of an economy or country (World Bank, 2011) ${ }^{[20]}$. The author remarks that it is very difficult to plan in a crisis, and unrealistic to plan for many years ahead except when an organization has some confidence that it will exist next year, and that most of its key staff and its Board leadership will continue to be affiliated with the organization.

A strategic plan is, is generally, a company's game plan.to compete successfully and results from serious managerial choices among numerous competing alternatives, and it indicates commitment to specific markets, policies, procedures, and operations in lieu of other, "less desirable" courses of action (David, 2011) ${ }^{[5]}$. According to Dyer, Godfrey, Jensen, \& Bryce $(2016)^{[6]}$ sometimes strategies are successful and sometimes they are not.

There are several limitations in the use of strategic management that shows that this method of management and, like others, is not universal for any situations and problems (Braduţan and Sârbu, 2012; Jurevičienè, 2013) ${ }^{[2,11]}$. They include;

a) Adverse effects may occur if people who formulate the strategy are not involved in its implementation, being difficult to assign individual tasks to other persons not involved in the.

b) Sharply increase the negative consequences of mistakes in strategic planning because in the short-term new products, investment directions radically change, when suddenly there are new business opportunities.

c) Strategic management cannot provide a precise and detailed picture of the future. Describing in detail the future of an organization is not a detailed description of its internal state and the situation in the external environment, but rather a mixture of qualitative wishes towards the state in which the organization wants to be in the future, what position to take in the market and in the business, what organizational culture to have. This may remain just wishful thinking giving false hope.

d) Strategic management cannot be limited to a set of routine rules, procedures and schedules and it being a theory that describes how and what to do to solve problems or situations as well as a philosophy or ideology of business and management every manager understands it and largely makes it in their own way hence a possible source of conflict.

e) Costly to perform for small and medium businesses because managers or strategic planners have to be hired, additional efforts are required towards analysis of external and internal environments and some tools need to be designed to properly implement strategic planning process.

f) The process is usually complex since it consists of many steps that are connected to each other and must be constantly adjusted time and again. In some cases, the process has to be repeated over and over again.

g) Low rate of successful implementation due to its complexity and heavy commitment to strategic goals. Often, the poor implementation is the reason for failure, although it is more often the case of misaligned operational and strategic goals.

h) Strategic planning requires knowledge, training and experience in the field and managers should have high conceptual skills and abilities to make strategic plans. However, some organizations lack such managers with the knowledge and skill to prepare strategic plans, whose effect is that the desired results will not be achieved leading in huge financial losses for the organization in pursuit of plans that will fail.

6. Recommendations for successful strategic management Organizations should put in place various measures to ensure successful strategic planning and implementation. According to Mohammed (2015), organizations should;

a) Budgeting process should be linked to strategic processes to ensure adequate financing of strategic activities.

b) All employees of the organization should understand the organizational strategic plans and contribute towards realization of organizational strategic goals.

c) Understand the global dynamics in business environment so that external factors do not ambush and cripple strategic implementation. 
d) Adequate motivation should be put in place to encourage staff to deliver on organizational strategic goals.

e) Organizations should hire, train and retain qualified personnel to support strategic processes besides motivating them to deliver.

f) Correct strategies should be identified, developed and implemented and avoid execution of wrong strategies.

\section{Conclusions}

Business strategies are basis of survival in a competitive business environment and should therefore well developed. A strategic plan is useless unless it is successfully implemented, and this requires a good evaluation plan. For effective strategy implementation, organizations should be oriented towards the recruitment of capable and motivated personnel, who based on their achievements should be promoted to higher levels of management hierarchy. The leaders of organizations and all staff members should have a vision for the direction of their organizations. This will encourage the creation of a culture of high performance. On the other hand, the increase of financial autonomy will increase the flexibility and ability to implement strategy. Strategies should be creative and innovative while their execution should be both effective and efficient. Quick and effective feedback will enhance monitoring and evaluation and facilitate strategy implementation and avoid or limit failure. Organizations should be customer oriented to deal with competition and hence proper strategy formulation and implementation. An effective strategic plan should be built on organizational strengths and take advantage of opportunities while overcoming or mitigating against the weaknesses and threats facing the business. It should however be noted that having a strategic plan does not always guarantee success, but a well-crafted, innovative and creative plan that is well executed will guarantee success.

\section{References}

1. Baroto MB, Arvand N, Ahmad FS. Effective Strategy Implementation. Journal of Advanced Management Science. 2014; 2(1):50-54. Retrieved from http://www.joams.com/uploadfile/2013/1225/20131225 044203610.pdf

2. Braduţan S, Sârbu A. Advantages and disadvantages of the strategic management in the current economic context, 2012. Retrieved from http://www.cedc.ro/media/MSD/Papers/Volume $\% 204 \%$ 20no\%201\%202012/MSD_9.pdf

3. Brinkschröder N. Strategy Implementation: Key Factors, Challenges and Solutions, 2004. Retrieved from https://essay.utwente.nl/66188/1/brinkschroeder_BA_M B.pdf

4. Bryson JM. Strategic planning process for public and nonprofit organization. Long Range Planning, 1988; 21(1):73-81. Retrieved from http://citeseerx.ist.psu.edu/viewdoc/download?doi=10.1 1.458.5630\&rep=rep1\&type $=$ pdf

5. David FR. Strategic management concepts and cases. Upper Saddle River, New Jersey: Prentice, 2011.

6. Dyer JH, Godfrey P, Jensen R, Bryce D. Strategic management: Concepts and tools for creating real world strategy. Hoboken, NJ: John Wiley \& Sons, 2016.

7. Glueck W. Business policy and strategy (3rd Ed). USA: McGaw Hill Publishing, 1980.
8. Heracleous L. The role of strategy implementation in organization development. Organization Development Journal. 2000; 18(3):75-86. Retrieved from https://www.researchgate.net/publication/291991105_T he_role_of_strategy

9. Hughes O. Public Management and Administration: An Introduction, (3rd Ed). Melbourne: MacMillan, 2003. Retrieved from https://rove.nla.gov.au/work/8182466

10. Hill CW, Jones GR. Strategic management, 4th Edition, Boston: Houghton Mifflin Company, 1998.

11. Jurevičienè G. Strategic planning advantages and disadvantages, 2013. Retrieved from http://strategicplanninginsights.blogspot.com/2013/04/a dvantages-and-disadvantages-of.html

12. Leskaj E. The challenges faced by the strategic management of public organizations. Administratie si Management Public, 2017; (29):151-161.

13. Mintzberg $\mathrm{H}$. The rise and fall of strategic planning: reconceiving roles for planning, plans, planners. New York: Free Press, 1994. Retrieved from https://hbr.org/1994/01/the-fall-And-rise-of-strategicplanning

14. Mohamed MA. Implementing strategy, 2015. Retrieved from http://vlib.moh.gov.my/cms/documentstorage/com.tms. cms.document.Document_9bb2e3e4

15. Ong C. 5 Benefits of Strategic Planning. Envisi, 2015. Retrieved from https://www.envisio.com/blog/benefitsof-strategic-planning

16. Porter, M. What is Strategy? Harvard Business Review, 1966, 61-78. Retrieved from https://hbr.org/1996/11/what-is-strategy

17. Poister T, Streib G. Elements of strategic planning and management in municipal government: Status after Two Decades. Public Administration Review. 2005; 65(1):4556. Retrieved from https://onlinelibrary.wiley.com/doi/abs/10.1111/j.15406210.2005.00429.x

18. Tanuja A. (nd.) Strategic Planning: Meaning, Importance and Limitation. Retrieved from http://www.businessmanagementideas.com/managemen t/strategic-Planning/strategic-planning-meaningimportance-and-limitation/4771

19. Tapera J. The importance of strategic management to business organizations. International Journal of Social science Management. 2016. Retrieved from https://www.researchgate.net/publication/301801352

20. World Bank Strategic planning: a ten-step guide, 2011. Retrieved

from https://siteresources.worldbank.org/INTAFRREGTOPT EIA/Resources/mosaica_10_steps.pdf 